DR. G. WILSON ON THE DETECTION OF FLUORINF.

\title{
XV.-On a New Process for the Detection of Fluorine when accompanied by Silica.
}

\section{By George Wilson, M.D.}

Having had occasion recently to examine several substances containing a small amount of fluorine, along with a large amount of silica, I have put in practice two processes, one of which is so easily managed, and has yielded such excellent results, that I bring it before the attention of the members of the Chemical Society.

The substances which I had to examine were the ashes of straw, hay, coal, and charcoal; and likewise granite, basalt, greenstone, and clinkstone, in the majority of which, fluorine has not hitherto been detected, nor, indeed, sought for, owing, doubtless, to the practical difficulties which attend the detection of fluorine when accompanied by much silica. The chief difficulty in such inquiries arises from the necessity of carrying on the analysis in vessels of platinum, which makes it impossible to subject large quantities of material to investigation.

The following process meets this difficulty, as it requires only the ordinary glass and porcelain vessels of the laboratory, and may be prosecuted with any amount of material. It is founded upon the very familiar fact, that when a fluoride, combined or mixed with silica, is heated with oil of vitriol, the fluorine and silicon are evolved in combination, as the well-known fluoride of silicon $\left(\mathrm{SiF}_{3}\right)$; and it is applicable to all silicated fluorides which yield this gas. It is further applicable to compounds containing mere traces of fluorides, but free from silica, which are brought within the compass of the process, by the deliberate addition of silica to them, so as to admit of their being heated in large quantity with oil of vitriol in glass vessels. In either case, the fluoride of silicon set free is conveyed by a bent tube from a flask or retort into water. The resulting solution, containing some gelatinous silica, is supersaturated with ammonia, and evaporated to dryness, during which process the fluoride of silicon and ammonium $\left(2 \mathrm{SiF}_{3}+3 \mathrm{NH}_{4} \mathrm{~F}\right)$ is resolved into silica, which is rendered insoluble, and fluoride of ammonium, which is dissolved by digesting water on the evaporated residue. The solution of the ammonio-fluoride is then evaporated to dryness, and heated with oil of vitriol, in a platinum crucible, covered by a piece of waxed glass, having lines traced through it, so as to permit the hydrofluoric acid evolved to etch the glass. I have tried this process 
with Peterhead and Aberdeen granite, with basalt from Arthur's Seat, greenstone from Corstorphine Hill, and clinkstone from Blackford Hill-all three in the neighbourhood of Edinburgh. I have also tried it with the ashes of barley-straw, of hay, of coal, and of charcoal; and in addition with a fossl bone, containing much carbonate of lime, and with a deposit from the boiler of an ocean steamer. To the bone and to the boiler deposit, pounded glass was first added. I lay before the Society some of the specimens obtained in this way. They are not selected successful ones, but represent the earliest trials. Where the rocks under examination have been weathered, or the substances (such as plant-ashes) have contained salts of volatile acids (for example, chlorides and carbonates), I have treated them first with oil of vitriol in the cold, so as to evolve hydrochloric acid and carbonic acid. On afterwards raising the liquid to the boiling-point, in a flask with a bent tube, a gas was given off, if fluorine were present, which deposited gelatinous silica when passed through water, and produced with it a solution which gave a gelatinous precipitate with potash. The whole of the fluoride of silicon is given off as soon as the oil of vitriol has reached its boiling-point. I am at present engaged in applying this process to a variety of substances, and in ascertaining its applicability to the quantitative determination of fluorine. I forbear, in the meanwhile, to enlarge upon the interesting geological, mineralogical, and physiological results which may be expected to flow from the discovery of fluorine in trap rocks, and the recognition of its comparative abundance in plants. 